doi: $10.12957 /$ childphilo.2020.48342

\title{
infancia, impulso y devenir creativo. aproximaciones nietzscheanas
}

\author{
juan pablo alvarez coronado 1 \\ universidad autónoma de chile, chile \\ orcid id: https:/ / orcid.org/0000-0003-3456-2282
}

\section{resumen}

En el pensamiento nietzscheano hay una tensión permanente entre la cultura y la vida; ambas se mueven, muchas veces, en contradictorias direcciones. Según Nietzsche, siempre gana la cultura, pues tiene de su parte la dimensión apolínea, es decir, ese modo definido, claro, refinado en el que se expresa, comprende y transmite lo narrado. Ahora bien, la formabella es apenas un modo de aparecer de lo profundamente trascendental, es la punta de un iceberg gigantesco llamado vida. Nietzsche es un pensador vitalista, apuesta por la expresión plenamente humana, consistente en querer, por amor a uno mismo, lo mismo que quiere la vida, es decir, encaminando sus acciones hacia la suspensión de los juicios acerca de aquello más conveniente, más adecuado, políticamente correcto, aquello que se ajusta a un registro de la cultura. La infancia tiene mucha vida presionando por salir, es la latencia dionisiaca que no quiere sucumbir al compromiso apolíneo, es la vida sin nombre, la fuerza que arrasa con todo enquistamiento de la forma. Es una vida y una infancia en tensión, una infancia que creemos conocer y al mismo tiempo una infancia que no será nunca esos nombres que le damos. Con frecuencia la captura y la clausura moviliza nuestro interés adulto, nos acercamos a la infancia poniéndole nombres y asignándole roles, vamos dándole forma a lo informe. El impulso lo convertimos en pulso, en cadencia, en registro, en tic-tac, Cronos aparece, el ser adquiere forma permanente, el devenir se va poco a poco desvaneciendo.

palabras clave: nietzsche; infancia; voluntad de poder; vitalismo.

\section{childhood, impulse and creative becoming. nietzschean approaches}

\begin{abstract}
In Nietzschean thought there is a permanent tension between culture and life; both move, many times, in contradictory directions. According to Nietzsche, culture always wins, because it has the Apollonian dimension on its part, that is, that defined, clear, refined way in which it is expressed, understands and transmits what is narrated. The beautiful form is just a way of appearing from the deeply transcendental; it is the tip of a gigantic iceberg called life. Nietzsche is a vitalist thinker, committed to human expression, consisting of wanting, for love of oneself, the same thing that life wants, that is, directing its actions toward the suspension of judgments about the most convenient, most appropriate, politically correct, forms of cutural life. Childhood has an abundance of life pushing to get out--it is the Dionysian latency that does not want to succumb to the Apollonian commitment; it is life without a name, the force that devastates the encystment of form. It is life and childhood in tension, a childhood we think we know and at the same time a
\end{abstract}

${ }^{1}$ E-mail: jp.alvarezcoronado@gmail.com 
infancia, impulso y devenir creativo. aproximaciones nietzscheanas

childhood that will never match those names we give it. Frequently the impulse for capture and closure mobilizes our adult interest, we approach childhood by naming and assigning roles, we are shaping the account we give of it. The impulse is converted into a pulse, a cadence, a recording, a ticking; Cronos appears, being acquires a permanent form, becoming gradually fades away.

keywords: nietzsche; childhood; the will to power; vitalism.

resumo

\section{infância, impulso e devir criativo. aproximações nietzscheanas}

No pensamento nietzscheano há uma tensão permanente entre a cultura e a vida; ambas se movem, muitas vezes, em contraditórias direções. Segundo Nietzsche, sempre ganha a cultura, pois tem a seu lado a dimensão apolínea, quer dizer, esse modo definido, claro, refinado em que se expressa, compreende e transmite o narrado. Contudo, a forma-bela é apenas um modo de aparecer do profundamente transcendental, é a ponta de um iceberg gigantesco chamado vida. Nietzsche é um pensador vitalista, aposta na expressão plenamente humana, consistente em querer, por amor a si mesmo, o mesmo que quer a vida, ou seja, encaminhando suas ações na direção da suspensão dos juízos acerca daquilo mais conveniente, mais adequado, politicamente correto, aquilo que se ajusta a um registro da cultura. A infância tem muita vida pressionando para sair, é a latência dionisíaca que não quer sucumbir ao compromisso apolíneo, é a vida sem nome, a força que devasta com todos os pedidos de forma. É uma vida e uma infância em tensão, uma infância que acreditamos conhecer e ao mesmo tempo uma infância que não será nunca esses nomes que lhes damos. Com frequência a captura e o encerramento mobiliza nosso interesse adulto, nos aproximamos da infância colocando-lhe nomes e atribuindo-lhe papéis, vamos dando uma forma ao informe. O impulso convertemos em pulso, em cadência, em registro, em tic-tac, Cronos aparece, o ser adquire forma permanente, o devir vai pouco a pouco desvanecendo.

palavras-chave: nietzsche; infância; vontade de poder; vitalismo. 
infancia, impulso y devenir creativo.

aproximaciones nietzscheanas

\section{infancia y vida}

Regularmente pensar en la infancia es pensar también en las condiciones que permiten su aparición, es decir, en aquellas características psicológicas, sociológicas, históricas sobre las cuales se asienta esa etapa del desarrollo vital de una persona. Así mismo, pensarla es pensar sus modos de aparición, las maneras en que ellas se muestran, se conocen y reconocen en medio de las culturas.

Con menos regularidad se piensa que la infancia podría ser la latencia de una tensión en el límite de sus ideas más frecuentes. Si estas últimas apuntan a la consolidación de una ontología infantil, tras la cual es posible edificar una arquitectónica de la infancia, las ideas menos frecuentes nos permiten sospechar del suelo sobre el cual se ha edificado. En este sentido, serán algunas ideas del filósofo Friedrich Nietzsche, acostumbrado a demoliciones arquitectónicas, las que nos ayudarán a profundizar en esta sospecha. No olvidemos que uno de sus proyectos más interesantes consistía en desenmascarar esa metafísica que asentaba lo ontológico sobre un carácter de inmutabilidad y permanencia. Ahora bien, avanzar hacia una concepción de infancia cuyo rasgo característico sea la estabilidad y la permanencia resulta desmedido respecto de la diversidad de expresiones desde las cuales las infancias tienen lugar. Con Nietzsche se nos abre la posibilidad de pensar que las infancias solo permanecen mientras devienen, que su ser no es la pura aparición presente sino la constante tensión entre presencia y ausencia, que su ser, finalmente, es el puro devenir.

Nietzsche lleva a cabo su 'transmutación de todos los valores' a partir de una crítica dirigida hacia la absolutización que a lo largo de la historia han sufrido determinados valores, convirtiéndose, de este modo, en valores canónicos. Si bien estamos en un terreno axiológico, también se trata de cuestiones epistemológicas. Tanto el valor que le asignamos a los valores morales como el valor epistémico que 
infancia, impulso y devenir creativo. aproximaciones nietzscheanas

le otorgamos a "la verdad", a su parecer, sólo operarían desde determinadas 'perspectivas de utilidad' y no constituirían ni garantizarían, por lo tanto, ningún tipo de imparcialidad ni de objetividad,

el mérito histórico de Nietzsche fue entender con más claridad que cualquier otro filósofo, y desde luego con más claridad que sus homólogos anglosajones emotivistas y los existencialistas continentales, no sólo que lo que se creía apelaciones a la objetividad en realidad eran expresiones de la voluntad subjetiva, sino también la naturaleza de los problemas que ello planteaba a la filosofía moral. (Macintyre, 2004, p.146)

Será en esta voluntad subjetiva en la cual Nietzsche descubrirá la fuente de los valores y en virtud de ello, la responsabilidad que le cabe al designar lo que es o no valioso, de acuerdo con una determinada utilidad prestada para la vida individual y la auto conservación. En este sentido, leemos a Nietzsche a través de ese alter ego llamado Zaratustra: "El valorar mismo es el tesoro y la joya de todas las cosas valoradas. Sólo por el valorar existe el valor: y sin el valorar estaría vacía la nuez de la existencia" (Nietzsche, 2000, p.100)

De este modo surge el planteamiento de que, para Nietzsche, además de que el valor de las cosas se crea a partir de la valoración que de ellas se realiza, "el único fundamento del valor en general es lo valioso para la vida" (ESCRIBAR, A., 1982, p.6). Si desplazáramos esta idea hacia el plano de la infancia nos encontraríamos con una perspectiva vitalista, que invita a pensar el territorio infantil como una experiencia definida por sus modos genuinos de sumar más vida a la vida, y donde el carácter inanticipable de lo sumado está directamente relacionado con su potencialidad y desarrollo. Dicho de otro modo, no se trata de que la vida de la infancia sea valorada porque esta se ajusta a una forma esperada de lo infantil, sino por tratarse de una expresión vital que desborda todo lo infantil conocido.

A simple vista, este vitalismo nietzscheano parece encerrar una afirmación clara de subjetivismo, sin embargo, sólo lo es en cierta medida. No lo es, por ejemplo, si con ello se afirmara que Nietzsche eleva la particularidad del sujeto, sus límites y propios intereses por sobre los intereses de la comunidad. Esta afirmación sería 
posible de atribuir a una perspectiva egoísta, pero Nietzsche no parece pensar aquel 'subjetivismo' en términos 'yoístas'.

El ' $\mathrm{yo}^{\prime}$ nietzscheano se presenta ante los otros como centro, pero no únicamente en términos de primacía del sujeto por sobre todo lo demás, sino que emerge sólo después de haber comprendido que en la base de cualquier valoración se mantendría activo algo así como un 'impulso', lo que se llamó anteriormente 'perspectiva de utilidad' y que lleva al sujeto a valorar las cosas, por lo cual, en último término, sería este impulso quien tendría la primacía y no el sujeto mismo. Esta 'actividad interior' es lo que Nietzsche llamó voluntad de poder. Voluntad que nace desde la vida misma y no tiene otra finalidad ni objeto que la vida misma. Se trataría, al fin y al cabo, de una voluntad sin voluntariedad subjetiva, una voluntad que no se elige, sino que más bien se padece.

Por ello su exteriorización, inevitablemente reconocible a través de manifestaciones y acciones subjetivas, no comportará en sí misma otra voluntad que la voluntad de vida que la originó y que la impulsa, con indiferencia respecto de los contextos, las formas imperantes de la cultura y las normas sociales instituidas.

En este sentido, quizás las preguntas dirigidas a las manifestaciones creativas de la infancia tengan en su base algo parecido a esa voluntad que Nietzsche sitúa a la base de la acción humana. Es lo vital frente a lo cultural, la vida que excede la expresión subjetiva a través de la cual se hace reconocible ella misma en una cultura de la presencia. Conocemos la vida humana en función de la expresión subjetiva que adquiere. La vida sigue siendo muchísimo más extensa y profunda que la manifestación específica que debe adoptar, pero sabe que, sin esta última, sería muy difícil nombrarla. Con la infancia parece ocurrir lo mismo, la reconocemos por sus manifestaciones particularizadas, la nombramos por ellas, pero ella sigue excediendo por mucho el desgarro que constituye su compromiso de aparición.

Dando un paso más, podemos decir que toda acción creativa (también política, moral, etc.) que se realiza en medio de una sociedad, y que ante los ojos de todos afecta a algunos, sea para ellos o contra ellos, estaría motivada por la voluntad 
infancia, impulso y devenir creativo. aproximaciones nietzscheanas

de poder y no por la inclinación particular del sujeto. Si, por ejemplo, como consecuencia de un acto, se perjudica o se beneficia a alguien, esto no es atribuible a la mala o buena intención del sujeto, sino a la fidelidad con que éste lleva a cabo la voluntad de poder que se manifiesta y afirma a través de tal acto. Es el clásico ejemplo utilizado en la Genealogía de la Moral (Nietzsche, 1991, p.51) para referirse al injustificado rencor que los corderos tienen hacia las aves de rapiña porque éstas les arrebatan a sus corderitos. Injustificado resulta, pues toda ave de rapiña tiene en sí misma, tanto la capacidad como la necesidad de expresar su fuerza en la búsqueda de alimentos, mediante la cual su afán no constituye una falta sino simplemente autoconservación. La crueldad con que mata a los corderitos no es en modo alguno atribuible a un acto malvado o resentido, ni debido a que exista otra motivación que no sea exclusivamente la de conservarse y en esa conservación permitir la expresión de su constitución más íntima, la de ser, precisamente, un ave de rapiña.

De esta manera, parece muy difícil hablar de que el sujeto moral nietzscheano actúe en términos de bueno o malo, sino que más allá de esto, la expresión subjetiva solo lleva a cabo la afirmación de una 'fuerza' aún mayor, que no proviene de la finitud del sujeto sino de una cósmica experiencia, que indiferente a toda forma social o cultural que hoy reconozcamos, sólo busca ser plenamente, es decir, sólo se busca a ella misma.

Con la infancia y sus formas de expresión y creación, puede pasar lo mismo que con el ave de rapiña, su acción puede ser vista como una afrenta a una cultura de la forma, del trazo verosímil, del color preciso. Su arte, en cambio, no alcanza a llegar, se queda corto, se queda en el bosquejo frente a una obra terminada, y ni siquiera eso, pues hasta el bosquejo ya tiene una forma reconocible, tiene un nombre que lo captura y permite su calificación: hay bosquejos buenos y bosquejos malos. La confusión entre el ser y el valor se instala. El valor se sustancializa, se calcifica, mostrando su cara más dura, donde él mismo siempre aparece justificando su propia teleología. La valoración pierde importancia frente al valor y la creación pierde importancia frente a lo creado. Importa la forma final en la medida que permita ser 
situada y reconocida de alguna manera y no la tensión, titubeo, incluso negación, del proceso que la ha vehiculizado. La 'infancia de rapiña', sin embargo, no es culpable de hacer lo que hace y no le interesa causar un daño a las sensibilidades artísticas, pedagógicas o familiares; tampoco le mueve lo contrario. Si su acción o creación es celebrada por la vida adulta, seguramente será porque pudo ser reconocible dentro de alguno de los parámetros de la axiología de la asociación. La acción infantil que se parece a una acción "propia de un adulto", tiene un valor reconocido. La acción que los adultos no podemos circunscribir en ninguna parte, nos parece carente de valor.

\section{2. impulso y devenir}

El ser en Nietzsche, el ser de la vida en tanto voluntad de poder, no puede ser otra cosa que el devenir. Devenir que adquiere por primera vez en la metafísica contemporánea el carácter de ser y que se manifiesta como una fuerza empeñada en llevarse a cabo, empeñada en consumirse a ella misma, en llegar a ser lo que es, de modo que siendo ella puro devenir, su objeto, es decir, la finalidad hacia la cual la voluntad de poder se dirige, se vuelve ilimitada.

La aparición de aquello que no tiene medida ni límite adquiere carácter cósmico, que para Nietzsche sería algo así como la resistencia frente al compromiso apolíneo de representatividad basado en lo racional, en el control y la forma finita. Esta aparición significa también el ingreso de la vida terrenal a la dimensión de lo dionisíaco, abrazando una sensualidad desatada, informe y caótica. Sin embargo, este ingreso debe comprenderse como la "entrega a la disolución, a la superación del desgarro de la fragmentariedad de la que es culpable toda existencia particular" (Carrasco, 2000, p.18) Es el devenir anulando la particularidad, la subjetividad de un yo artista, de un yo infante, de un yo creador. Es la vida informe y desatada la que se quiere expresar, el artista, el infante o el creador simplemente prestan sus formas, sus manos, su voz, para que algo de aquel impulso vital aparezca de modo reconocible para los demás. Mientras más cultura haya sumado sobre sus hombros 
infancia, impulso y devenir creativo. aproximaciones nietzscheanas

un creador, mayores serán los filtros que deberá sortear la expresión de la vida, mayor conciencia de aquellos repartos de lo sensible (Rancière, 2009) que delimitan los lugares y los fuera de lugar, mayor conciencia de los ordenamientos discursivos que "nos impiden decirlo todo en cualquier circunstancia" (Foucault, 1992, p.11).

Esta entrega a la disolución dionisiaca no es como podría pensarse, de una vez y para siempre. La afirmación del devenir es el sí del ser humano a su vida en tanto cambio incesante, por ende, nunca será una tarea acabada, siempre estará de camino para llegar a ser el que es.

La infancia, en este sentido, sabe mucho de este asunto, pues con demasiada frecuencia se la sitúa a medio camino entre dos ausencias. Educamos a la infancia para que deje de serlo, y cuando creemos que ha dejado de serlo, le pedimos a ella misma (ya ausente) que se comporte como otra cosa. Le pedimos lo que no alcanzamos a comprender, pues aquí infancia es sinónimo de vida, y no podemos pedirle a la vida que no se comporte como ella misma. La infancia es cambio en las reglas del juego, es desorden de los discursos, es expectativa frustrada, contradicción permanente entre apariencia y desaparición. La vida es pura infancia, la infancia es puro impulso vital.

Nietzsche avanza más. Esta entrega a la disolución en el ser-devenir se presenta siempre para todo sujeto como una opción y una posibilidad, al igual que en la gran mayoría de las concepciones óntico-ontológicas del ser humano, éstas han tenido la posibilidad de manifestarse en la vida de manera auténtica o inauténtica. Las infancias más literales, en este sentido, tienen la ventaja de los inicios, pues al desconocer otras formas culturales de expresión, su compenetración con el devenir vital se da de manera fluida y privilegiada.

Para Nietzsche, recordemos que hablamos de sus polémicos primeros escritos, el hombre fuerte, el noble, el aristócrata, el <bien nacido $>$, será quien asuma su vida en plenitud, haciendo coincidir, o más bien, padeciendo la coincidencia, de que su voluntad quiera lo mismo que quiere la vida. De este modo, al ser asumida e integrada la vida en toda su diafanidad, ella aparece ante el mundo como el 
resultado de una voluntad exclusivamente subjetiva, en circunstancias que, para Nietzsche, el sujeto mismo, como 'agente' que mueve la acción, no es de real importancia, de hecho, ha descrito al sujeto "como un hijo falso y un infiltrado en la vida de los hombres" (Nietzsche, 1991, p.52). Le interesa más bien la acción misma, pues es en ella donde se encuentra actuando su verdadero 'agente', ella misma es manifestación de la voluntad de poder que tiene la vida, o mejor dicho, es la manifestación de la vida en tanto voluntad de poder.

La vida del sujeto fuerte se cumple en la medida que su fortaleza se exterioriza a sí misma como potencia, no en cuanto el sujeto persevere en querer mostrarse de esa manera: "no hay detrás del fuerte un sustrato indiferente, que fuera dueño de exteriorizar y, también, de no exteriorizar fortaleza" (Nietzsche, 1991, p.52). No existe por tanto un sujeto reconocible tras "el fuerte" que lo haga aparecer como tal, sino que es la realización espontánea de las acciones la que manifestará su disolución en la voluntad de poder y expresará su 'ser fuerte' de manera libre y autónoma.

Una infancia fuerte podríamos reconocerla si vamos siendo capaces de suspender, de silenciar, todo lo que creemos saber de ella, pues las formas del saber son también formas apolíneas de la descripción, de la prescripción y de la clausura. Esas formas son también nuestras trincheras de la debilidad y del temor que nos produce estar frente a una estética informe y a un impulso que en su descontrol echa abajo nuestros diques culturales.

Todo esto ayuda a hacernos la idea de una expresión vital más genuina, aunque la tentación sea concebirla en términos de carencia, de adolescencia, como si el deber de toda cultura fuera el dominio de una situación pre-racional, pre-estética o pre-social que no alcanza aún a comprender y vivir bajo reglas y cánones sociales de convivencia. Nietzsche (1947, p.115) lo llamará, “un animal que aún no se ha logrado domesticar".

Ahora bien, este sujeto nietzscheano que escoge diluirse y afirmarse en la voluntad de poder, no puede evitar también negarse a sí mismo al negar la fragilidad 
infancia, impulso y devenir creativo. aproximaciones nietzscheanas

y el límite de su parte sensible, niega también ser sujeto social para volverse 'inimputable' moralmente pues su acción se instala más allá del bien y del mal y niega finalmente la vida que está viviendo en el momento presente, en virtud de afirmar la vida como devenir, como movimiento que al ser detenido, deja de existir. Todo esto corresponde a "la ambigüedad que habita en el pensamiento dionisíaco" (Carrasco, 2000, p.19). Es indisoluble el sí dicho a la vida, de un no a la situación presente y es también indisoluble el sí al carácter cósmico de la voluntad de poder, del no al carácter frágil de la existencia individual.

Lo dionisíaco es tan afirmativo como destructivo, se trata de una disolución de lo individual en el todo, pero como este "todo" es el puro devenir, es decir, algo que constantemente se niega y se devora a sí mismo, el movimiento necesariamente debe engendrar el espíritu de destrucción. (Carrasco, 2000, p.19)

Un espíritu destructivo destruye cada pretensión de instauración y fijación de determinados valores o escalas de valores, sean morales, estéticos o epistémicos. Propone una valoración que no se repite ni se realiza siempre de la misma manera, por lo tanto, que no reconoce mandatos ni tampoco imperativos normativos, sino que surge de la necesidad de un momento determinado de la vida, en que ésta escoge afirmarse a sí misma a través de acciones liberadas a su espontaneidad.

"Valorar es crear" ha dicho Zaratustra (Nietzsche, 2000, p.100), toda valoración es la creación de un nuevo valor, toda acción y conocimiento son instrumentos al servicio de la voluntad de poder creadora. Será pues en el descubrir ese carácter instrumental de la acción que se descubrirá también el 'sentido' de la misma, aquello que garantizará un valor a su existencia y librará al ser humano de encaminarse en dirección a la nada. Sin embargo, no se nos olvide que estos 'sentidos' son circunstanciales, no son los que siempre debieron ser, sino que son los que deben ser en este aquí y en este ahora, dependiendo cada vez de las diversas 'perspectivas de utilidad' con que la vida creadora se manifieste.

En cierto sentido, todo lo que aquí hemos descrito parece convertir al sujeto, incluido el sujeto de la infancia, en un simple portavoz de la voluntad de poder 
destinado a la creación y la acción. Podría pensarse que estamos ante un escenario cercano al de las marionetas, pero yo diría que es más cercano al del ventrílocuo, pues un ventrílocuo se define por su capacidad para hablar desde el vientre, y quizás de eso se trate todo en Nietzsche, de permitir el instinto, el impulso, la pulsión, eso que la vida misma necesita expresar y que la vida misma frena y contiene en la lucha con sus circunstancias. Una perspectiva de creación infantil en clave nietzscheana tiene, a mi juicio, como principal mérito descubrir aquello que la vida puede hacer a través de la infancia y no lo que siempre hacemos, que es evaluar lo que la infancia puede hacer en la vida.

\section{referencias}

Carrasco, E., El pensamiento dionisíaco, Revista de Filosofía Universidad de Chile, Vol. LV-LVI, 17-38, 2000.

Escríbar, A., Nietzsche: la vida como Fundamento del valor, Santiago, Chile, Publicaciones Especiales Facultad de Filosofía y Humanidades, Universidad de Chile, 1982

Foucault, M., El orden del discurso, Buenos Aires, Argentina, Tusquets Editores, 1992.

Nietzsche, F., Así habló Zaratustra, Madrid, España, Editorial Alianza, 2000

Nietzsche, F., Genealogía de la Moral, Madrid, España, Editorial Alianza, 1991

Nietzsche, F., La Voluntad de Poder, Buenos Aires, Argentina, Editorial Poseidón, 1947.

Macintyre, A., Tras la virtud, Barcelona, España, Editorial Crítica, 2004

Rancière, J., El reparto de lo sensible: Estética y política, Santiago de Chile, LOM Ediciones, 2009.

recibido en: 09.02.2020

aprobado en: 22.06.2020 